REALA, número 14, octubre-marzo de 2020

Sección: COMUNICACIONES Y COMENTARIOS JURISPRUDENCIALES

Recibido: 07-07-2020

Modificado: 22-09-2020

Aceptado: 23-09-2020

DOI: https://doi.org/10.24965/reala.i14.10825

Páginas: 161-179

\title{
Mancomunidades integrales en Extremadura: estrategia, trayectoria y revisión
}

\section{Integral municipal associations in Extremadura: strategy, trajectory and review}

\author{
Francisco Javier Durán García \\ Ayuntamiento de Villafranca de los Barros (España) \\ ORCID: https://orcid.org/0000-0002-3992-6949 \\ fcojavierdg@gmail.com
}

\section{NOTA BIOGRÁFICA}

Doctor en Fundamentos del Derecho, Derecho Económico y Derecho de la Empresa por la Universidad Pontificia de Comillas (ICADE), y funcionario de carrera como Letrado Asesor Jurídico del Ayuntamiento de Villafranca de los Barros. Su trayectoria como experto en Administración y Hacienda local viene avalada por la publicación de diferentes libros, ponencias y artículos sobre la materia, así como por la participación continuada como asesor en programas internacionales de cooperación municipal entre España y América Latina / Oriente Medio. Miembro de la Junta Directiva de la Asociación de Letrados de Entidades Locales de España.

\section{RESUMEN}

La Comunidad autónoma de Extremadura es una región española con una planta local formada mayoritariamente por pequeños Municipios; una estructura local decimonónica que se enfrenta a los problemas ocasionados por el inframunicipalismo y la despoblación. Ante esta situación, el Gobierno regional desarrolló y mantiene una estrategia territorial basada en la promoción de las Mancomunidades Integrales, una fórmula asociativa de carácter voluntario entre Municipios para la prestación de servicios. En el presente artículo se estudia, por una parte, la fundamentación y la trayectoria jurídica que soporta esta estrategia regional y, por otra, las principales carencias y debilidades que tiene el modelo a nivel institucional, administrativo, de recursos humanos y financiero. Además, se plantea la necesaria revisión de la estrategia regional y se ofrece una relación de puntos para un debate que se considera inaplazable.

\section{PALABRAS CLAVE}

Inframunicipalismo; Mancomunidades Integrales; Extremadura; estrategia territorial; planta local.

\begin{abstract}
The Autonomous Community of Extremadura is a Spanish region with a local level made up mostly of small municipalities; a nineteenth-century local structure that faces the problems caused by under-municipalism and depopulation. Faced with this situation, the regional government opted for a territorial strategy based on the promotion of the municipal associations called «Integral», a voluntary associative arrangement between municipalities for the provision of services. This article studies, on the one hand, the legal background behind this regional strategy and, on the other hand, the main gaps and weaknesses of this model at the institutional, administrative, human resources and financial spheres. In addition, it proposes the necessary revision of the regional strategy and offers a list of items for a urgent discussion.
\end{abstract}

\section{KEYWORDS}

Under-municipalism; integral municipal associations; Extremadura; territorial strategy; local level. 


\section{SUMARIO}

1. APROXIMACIÓN AL PROBLEMA DEL INFRAMUNICIPALISMO EN EXTREMADURA. 2. LA MANCOMUNIDAD COMO ESTRATEGIA. 2.1. ENTORNO JURÍDICO. 2.2. LA OPCIÓN EXTREMEÑA: MANCOMUNIDADES INTEGRALES. 3. TRAYECTORIA DE LA LEY 17/2010, DE 22 DE DICIEMBRE, DE MANCOMUNIDADES Y ENTIDADES LOCALES MENORES DE EXTREMADURA. 3.1. ANTECEDENTES NORMATIVOS. 3.2. EL ESPALDARAZO LEGISLATIVO. 3.3. HITOS POSTERIORES MÁS SIGNIFICATIVOS. 4. REVISIÓN: PUNTOS PARA UN DEBATE INAPLAZABLE. REFERENCIAS BIBLIOGRÁFICAS.

\section{APROXIMACIÓN AL PROBLEMA DEL INFRAMUNICIPALISMO EN EXTREMADURA}

Tomando como excusa el décimo aniversario de la Ley 17/2010, de 22 de diciembre, de Mancomunidades y entidades locales menores de Extremadura (LMELME) ${ }^{1}$, queremos hacer una reflexión jurídica sobre la trayectoria e impacto que ha tenido la estrategia asociativa en esta región española, especialmente en lo que se refiere a calibrar la eficacia desde su aprobación para afrontar los problemas y los retos que frecuentan en los pequeños Municipios.

Los Municipios en Extremadura, al igual que en el resto de España, son una pieza clave de la estructura territorial marcada por la vigente Constitución de 1978 (CE). Concretamente, su art. 140 determina que el modelo municipal en España se articula sobre el principio constitucional de autonomía local, además del de suficiencia financiera (art. $142 \mathrm{CE}$ ) y el de subsidiariedad (añadido por el derecho comunitario ${ }^{2}$ y cuya incidencia en el sistema competencial local es debatida). Por tanto, se constituye un régimen de descentralización política y administrativa, donde el texto constitucional otorga a los Municipios una doble condición, primero, como unidades dependientes que forman parte de la planta organizativa del Estado -el rol tradicional- y, segundo, como entidades con autonomía y personalidad jurídica plena -la novedad-.

Nos detenemos para profundizar en el concepto de autonomía local que acuña la CE acudiendo a la definición recogida en el art. 3 de la Carta Europea de la Autonomía Local de 1985 (CEAL) ${ }^{3}$, donde: «Por autonomía local se entiende el derecho y la capacidad efectiva de las Entidades locales de ordenar y gestionar una parte importante de los asuntos públicos, en el marco de la Ley, bajo su propia responsabilidad y en beneficio de sus habitantes». Con mayor precisión que nuestra Carta magna, la CEAL determina que la autonomía municipal es un derecho que va más allá del mero principio administrativo, de tal forma que los Municipios gozan de capacidad efectiva para resolver los asuntos de su competencia y para responsabilizarse de sus decisiones. El límite, comprensiblemente, lo marcan la legalidad vigente y el interés general de la vecindad.

Dicho lo anterior, a pesar del espaldarazo constitucional, la institución municipal se apoya en una planta local decimonónica donde las únicas variaciones sufridas han sido para alcanzar una mayor fragmentación. Así, es relevante tener en cuenta los datos facilitados por el INE, a saber, de los 388 Municipios existentes en Extremadura en 2019, unos 353 son Municipios que cuentan una población igual o inferior a 5.000 habitantes (el $90,97 \%$ ). Si bajamos el rango a población igual o inferior a 1.000 h., son todavía unos 217 Municipios (el $55,92 \%)^{4}$. Estos datos evidencian con rotundidad que la planta local extremeña está conformada casi en su totalidad por pequeños Municipios.

El reconocimiento constitucional y el posterior desarrollo legislativo de las bases del régimen local han dotado al Municipio de un importante elenco de competencias y de fuentes de financiación cuyo ejercicio supone, en síntesis, la concreción de la autonomía municipal. Por otra parte, el avance del modelo descentralizado -con sus altos y sus bajos- y las cláusulas genéricas recogidas en la legislación del régimen local (v. gr.: art. 28 Ley 7/1985, de 2 de abril, Reguladora de las Bases del Régimen Local -en adelante, LRBRL-, actualmente suprimido ${ }^{5}$ ) los Municipios no han cesado de ampliar su ámbito de actuación a través de competencias propias, impropias y complementarias, para intentar dar cobertura a las demandas ciudadanas que han ido incrementándose a la par que se consolidaba el Estado del Bienestar.

\footnotetext{
Publicado en DOE núm. 245, de 23-12-2010, y BOE núm. 9, de 11-01-2011.

Art. 5 del Tratado de la Unión Europea.

3 Instrumento de Ratificación, de 20 de enero de 1988, de la Carta Europea de 15 de octubre de 1985 de Autonomía Local, hecha

4 https://www.ine.es/jaxiT3/Tabla.htm?t=2913\&L=0, 15-01-2020.

5 Se suprime por el art. 1.11 de la Ley 27/2013, de 27 de diciembre, de racionalización y sostenibilidad de la Administración Local.
} en Estrasburgo. 
Esta progresiva complicación del marco legal, competencial y financiero de las entidades municipales sólo ha puesto más en evidencia la incapacidad de los pequeños Municipios para ejercer su autonomía de forma plena y efectiva. Se trata de un proceso paulatino de pérdida de facto de autonomía, en favor del tutelaje por parte de otras administraciones (Comunidades Autónomas, Diputaciones Provinciales y Diputaciones Forales). Actualmente, para muchos Municipios este proceso de fuga de autonomía se antoja difícilmente reversible si observamos la tendencia en las zonas rurales. Es el caso de las dos provincias extremeñas, caminando hacia la pérdida de población de forma desordenada y sin control, y manteniendo a la institución municipal con una condición de gran dependiente cuya supervivencia precisa de otras administraciones. Es, en definitiva, lo que ya hemos denominado en otras ocasiones la situación de «minoría de edad permanente» de los pequeños Municipios (Durán, 2019: 142).

Así las cosas, la estructura municipal extremeña ya era débil en 1978 pues venía de sufrir el envite del proceso migratorio ocasionado por el desarrollismo español (Cayetano, 2007: 1.275-1.310), pero el avance del Estado descentralizado se convirtió en un reto casi impracticable para la planta municipal de Extremadura; donde los pequeños Municipios -la mayoría- eran incapaces de ejercer su autonomía local en condiciones de igualdad al resto y, lo que es más importante, donde la ciudadanía rural acusaba desventaja en la recepción de servicios públicos.

\section{LA MANCOMUNIDAD COMO ESTRATEGIA}

\subsection{Entorno jurídico}

En Europa, para superar las dificultades del inframunicipalismo se han venido planteado diferentes estrategias territoriales desde las primeras décadas de la segunda mitad del s. XX, a fin de alcanzar un nivel eficiente de capacidad organizativa en la planta municipal -Para profundizar sobre esta cuestión (Durán, 2016)-. Se trata de un problema al que se han enfrentado la gran mayoría de gobiernos europeos a medida que el diseño de sus estructuras locales ha quedado obsoleto. En síntesis, siguiendo la expresión generalizada por el Prof. Heinelt atendiendo a la localización geográfica de los países pioneros en acometer estas reformas (Bayona, 2012: 232), podemos distinguir:

1. "Estrategia del Norte de Europa", donde se defiende la fusión de pequeños Municipios, generalmente coercitiva y organizada, como mecanismo. El objetivo principal es constituir Municipios más grandes desde los puntos de vista territorial, demográfico, político y financiero, que alcancen viabilidad suficiente para prestar los servicios que demanda la ciudadanía al Municipio, al amparo de las tendencias que desarrollan el Estado del Bienestar (Heinelt, 2012: 86).

2. "Estrategia del Sur de Europa" donde se propugna por mantener la planta tradicional de pequeños Municipios y se articular la prestación de nuevos servicios a través de fórmulas asociativa de carácter voluntario.

En el caso concreto de España, la Constitución de 1978 sienta las bases propicias para que se desarrolle el pluralismo asociativo municipal (Orduña, 2009: 110). Entre las disposiciones que refrendan este propósito encontramos el art. 22 sobre el derecho de asociación (aplicación extensiva), el art. 141.3 que prevé la posibilidad de agrupaciones de Municipios diferentes a la división provincial, y el art. 152.3 que arroga a los Estatutos de Autonomía la facultad de establecer circunscripciones territoriales propias, mediante la agrupación de Municipios limítrofes. En consonancia con el mandato constitucional, la LRBRL reconoce también la posibilidad de las Comunidades Autónomas para crear en su territorio Comarcas u otras Entidades que agrupen Municipios (art. 42), así como la cooperación económica, técnica y administrativa entre la Administración local y las Administraciones del Estado y de las Comunidades Autónomas mediante los consorcios o los convenios administrativos (art. 57), y, finalmente, la capacidad para constituir asociaciones, de ámbito estatal o autonómico, para la protección y promoción de sus intereses comunes (DA 5. ${ }^{a}$ ). Por último, hacemos mención al art. 10 CEAL por el que se reconoce a nivel europeo el derecho de los Municipios, en el ejercicio de sus competencias, de cooperar y, en el ámbito de la Ley, asociarse con otras Entidades locales para la realización de tareas de interés común.

En la legislación autonómica está también presente esta estrategia a través de agrupaciones municipales, al haber sido la elegida por varias Comunidades Autónomas como opción para configurar la organización periférica de su administración o para planificar el territorio autonómico. Esta forma de fragmentar el 
territorio a través de comarcas se asume, entre otros, en los planes subregionales de ordenación del territorio de Andalucía ${ }^{6}$, en los planes de desarrollo comarcal de Galicia ${ }^{7}$, en las demarcaciones de La Rioja ${ }^{8}$, en el proceso de comarcalización en Aragón ${ }^{9}$ y Asturias ${ }^{10}$, o la organización comarcal de Cataluña ${ }^{11}$.

\subsection{La opción extremeña: Mancomunidades Integrales}

Sobre la base legal expuesta anteriormente, el tipo mancomunado de asociación está contemplado entre las técnicas de cooperación interadministrativas que reconoce la Ley de Bases junto a los consorcios. Así, el art. 44 LRBRL reconoce el derecho a la asociación para ejecutar en común obras y servicios de su competencia y, además, regula sucintamente lo referente a los integrantes, personalidad y capacidad, estatutos y vida jurídica. A diferencia de la comarca -que es una estructura establecida desde la instancia autonómica- las Mancomunidades surgen de aglutinar la voluntad municipal, sin embargo en Extremadura, la puesta en marcha y la continuidad de la gran mayoría ha sido promovida e incentivada económicamente desde la propia Administración regional.

Además de la participación voluntaria, estas Entidades locales se caracterizan por estar compuestas sólo por Municipios ( $v$. gr.: a diferencia de los consorcios que incorporan diferentes tipos de Administraciones); por tener una organización flexible que puede evolucionar en función de las modificaciones incorporadas en sus estatutos; y porque no precisan estar conformadas por territorios contiguos (aunque en la lógica es lo deseable para que sea eficaz). El número y alcance de los servicios que prestan es muy diverso ya que varía, siempre dentro del marco permitido por la ley, en función de la voluntad de los Municipios integrantes.

En un intento de solventar las disfunciones que conlleva el inframunicipalismo diagnosticado, el Gobierno extremeño asumió la cooperación municipal a través de la creación de estructuras intermunicipales, como estrategia territorial para la progresiva implantación de nuevos servicios en el ámbito municipal y como un intento de aplicar economías de escala en la gestión/financiación de estas demandas.

Concretamente fue en el año 2003, desde la recién creada Consejería de Desarrollo Rural ${ }^{12}$ y su Dirección General de Administración Local ${ }^{13}$, cuando se promovió la estrategia de reordenar las Mancomunidades preexistentes con el fin de constituir una red de entidades supramunicipales que abarcara ordenadamente a todos los Municipios de la región, primero, al amparo de la legislación básica del Estado y, posteriormente, dotándola de su propia ley especial. En el foro político se empezó a utilizar el término de «Mancomunidad Integral» (en adelante, M. I.) para diferenciarla del tipo tradicional, en la medida que estas nuevas entidades tenían como objeto prestar conjuntamente una cartera de servicios, en gran medida, más extensa y más variada a los tradicionalmente asociados a las Mancomunidades ( $v$. gr.: gestión del agua, arreglo de caminos).

Aunque abordaremos el análisis del texto legal autonómico en el siguiente epígrafe, es adecuado adelantar la definición legal que se acuña en su exposición de motivos para este nuevo tipo de Mancomunidad, según la cual:

«la Mancomunidad Integral, especie dentro del género de las Mancomunidades, como un instrumento con vocación de permanencia, a través del cual Municipios y entidades locales menores colindantes en lo territorial y que comparten una realidad económica, social y cultural, o una tradición propia común, puedan estructurar en conjunto la prestación de sus servicios, de una parte, y las políticas de desarrollo y promoción de sus poblaciones, compatibilizándolas con las singularidades y especificidades de los diferentes territorios de nuestra Comunidad Autónoma.».

6 Capítulo II, Ley 1/1994, de 11 de enero, de ordenación del Territorio de la Comunidad Autónoma de Andalucía.

7 Ley $7 / 1996$, de 10 de julio, de desarrollo comarcal de Galicia.

8 Capítulo IV, Ley 1/2003, de 3 de marzo, de la Administración Local de La Rioja.

9 Decreto Legislativo 1/2006, de 27 de diciembre, del Gobierno de Aragón, por el que se aprueba el Texto refundido de la Ley de Comarcalización de Aragón.

10 Ley 3/1986, de 15 de mayo, por la que se regula el procedimiento de creación de comarcas en el Principado de Asturias.

11 Decreto Legislativo 4/2003, de 4 de noviembre, por el que se aprueba el Texto refundido de la Ley de la organización comarcal de Cataluña.

12 Decreto del Presidente 15/2003, de 27 de junio, por el que se modifican la denominación y el número de las Consejerías que conforman la Administración de la Comunidad Autónoma de Extremadura.

13 Decreto 82/2003, de 15 de julio, por el que se establece la estructura orgánica de la Consejería de Desarrollo Rural. 
REALA. Nueva Época - N. 14, octubre 2020 - ISSN: 1989-8975 - DOI: https://doi.org/10.24965/reala.i14.10825 - [Págs. 161-179]

Mancomunidades integrales en Extremadura: estrategia, trayectoria y revisión

Francisco Javier Durán García

En la actualidad sigue vigente esta estrategia, auspiciada por todos gobiernos regionales que se han sucedido con distinto signo político. A fin de dar a conocer la envergadura de esta red autonómica, pasamos a referir algunos datos que denotan su expansión por toda la planta local extremeña, atendiendo a los criterios legales para obtener la calificación de «Integral» y a la información recogida en el Registro de Entidades Locales ${ }^{14}$, podemos aportar la siguiente relación:

TABla 1. MM. Integrales de la Provincia de Badajoz

\begin{tabular}{|c|c|}
\hline Denominación & Municipios asociados \\
\hline M. I. de Municipios Centro & $\begin{array}{l}\text { Alange; Aljucén; Arroyo de San Serván; Calamonte; Carrascalejo, El; Don Álvaro; } \\
\text { Mirandilla; Oliva de Mérida; San Pedro de Mérida; Trujillanos; Valverde de Mérida; } \\
\text { Villagonzalo; Zarza, La. }\end{array}$ \\
\hline M. I. Cíjara & $\begin{array}{l}\text { Castilblanco; Fuenlabrada de los Montes; Helechosa de los Montes; Herrera del } \\
\text { Duque; Valdecaballeros; Villarta de los Montes. }\end{array}$ \\
\hline $\begin{array}{l}\text { M. I. de Municipios } \\
\text { Guadiana }\end{array}$ & Cristina; Guareña; Manchita; Medellín; Mengabril; Santa Amalia; Valdetorres. \\
\hline $\begin{array}{l}\text { M. de Municipios } \\
\text { de La Serena }\end{array}$ & $\begin{array}{l}\text { Benquerencia de la Serena; Cabeza del Buey; Capilla; Castuera; Esparragosa de la } \\
\text { Serena; Higuera de la Serena; Malpartida de la Serena; Monterrubio de la Serena; } \\
\text { Peñalsordo; Quintana de la Serena; Valle de la Serena; Zalamea de la Serena; Zarza- } \\
\text { Capilla. }\end{array}$ \\
\hline $\begin{array}{l}\text { M. de Servicios } \\
\text { La Serena-Vegas Altas }\end{array}$ & $\begin{array}{l}\text { Campanario; Coronada, La; Haba, La; Magacela; Navalvillar de Pela; Orellana la Vieja; } \\
\text { Rena; Villanueva de la Serena; Villar de Rena. }\end{array}$ \\
\hline M. I. Lácara-Los Baldíos & $\begin{array}{l}\text { Alburquerque; Carmonita; Codosera, La; Cordobilla de Lácara; Nava de Santiago, La; } \\
\text { Puebla de Obando; Roca de la Sierra, La; Villar del Rey. }\end{array}$ \\
\hline $\begin{array}{l}\text { M. I. de la Comarca } \\
\text { de Olivenza }\end{array}$ & $\begin{array}{l}\text { Alconchel; Almendral; Barcarrota; Cheles; Higuera de Vargas; Olivenza; Torre de } \\
\text { Miguel Sesmero; Táliga; Valverde de Leganés; Villanueva del Fresno. }\end{array}$ \\
\hline M. I. La Siberia & $\begin{array}{l}\text { Baterno; Casas de Don Pedro; Esparragosa de Lares; Garbayuela; Garlitos; Puebla de } \\
\text { Alcocer; Risco; Sancti-Spíritus; Siruela; Talarrubias; Tamurejo. }\end{array}$ \\
\hline M. I. Sierra Suroeste & $\begin{array}{l}\text { Higuera la Real; Jerez de los Caballeros; Oliva de la Frontera; Salvaleón; Salvatierra de } \\
\text { los Barros; Valencia del Mombuey; Valle de Matamoros; Valle de Santa Ana; Zahínos. }\end{array}$ \\
\hline $\begin{array}{l}\text { Mancomunidad Turística y } \\
\text { de Servicios } \\
\text { de Tentudía }\end{array}$ & $\begin{array}{l}\text { Bienvenida; Bodonal de la Sierra; Cabeza la Vaca; Calera de León; Fuente de Cantos; } \\
\text { Fuentes de León; Monesterio; Montemolín; Segura de León. }\end{array}$ \\
\hline $\begin{array}{l}\text { Mancomunidad } \\
\text { «Zona de Barros» }\end{array}$ & $\begin{array}{l}\text { Aceuchal; Albuera, La; Almendral; Corte de Peleas; Entrín Bajo; Santa Marta; Solana } \\
\text { de los Barros; Torre de Miguel Sesmero; Villalba de los Barros. }\end{array}$ \\
\hline $\begin{array}{l}\text { M. I. Tierra de Barros-Río } \\
\text { Matachel }\end{array}$ & $\begin{array}{l}\text { Hinojosa del Valle; Hornachos; Palomas; Puebla de la Reina; Puebla del Prior; Ribera } \\
\text { del Fresno; Villafranca de los Barros. }\end{array}$ \\
\hline $\begin{array}{l}\text { M. I. de Servicios Vegas } \\
\text { Bajas }\end{array}$ & $\begin{array}{l}\text { Esparragalejo; Garrovilla, La; Guadiana; Lobón; Montijo; Puebla de la Calzada; } \\
\text { Pueblonuevo del Guadiana; Talavera la Real; Torremayor; Valdelacalzada. }\end{array}$ \\
\hline $\begin{array}{l}\text { M. de Municipios } \\
\text { Río Bodión }\end{array}$ & $\begin{array}{l}\text { Alconera; Atalaya; Burguillos del Cerro; Calzadilla de los Barros; Feria; Fuente del } \\
\text { Maestre; Lapa, La; Medina de las Torres; Morera, La; Parra, La; Puebla de Sancho } \\
\text { Pérez; Santos de Maimona, Los; Valencia del Ventoso; Valverde de Burguillos; Zafra. }\end{array}$ \\
\hline $\begin{array}{l}\text { Mancomunidad Integral } \\
\text { de Aguas y Servicios } \\
\text { de la Comarca de Llerena }\end{array}$ & $\begin{array}{l}\text { Ahillones; Azuaga; Berlanga; Campillo de Llerena; Casas de Reina; Fuente del Arco; } \\
\text { Granja de Torrehermosa; Higuera de Llerena; Llera; Llerena; Maguilla; Malcocinado; } \\
\text { Peraleda del Zaucejo; Puebla del Maestre; Reina; Retamal de Llerena; Trasierra; } \\
\text { Usagre; Valencia de las Torres; Valverde de Llerena; Villagarcía de la Torre. }\end{array}$ \\
\hline $\begin{array}{l}\text { Mancomunidad de } \\
\text { Municipios de la Comarca } \\
\text { de Fregenal de la Sierra }\end{array}$ & $\begin{array}{l}\text { Bodonal de la Sierra; Cabeza la Vaca; Fregenal de la Sierra; Fuentes de León; } \\
\text { Higuera la Real; Segura de León; Valverde de Burguillos. }\end{array}$ \\
\hline
\end{tabular}

Fuente: Elaboración propia a partir de los datos del Registro de Entidades Locales. https://ssweb.seap.minhap.es/REL/frontend/inicio/index.

14 Ministerio de Hacienda y Administraciones Públicas. Registro de entidades locales. Mancomunidades en Extremadura. https:// ssweb.seap.minhap.es/REL/frontend/inicio/mancomunidades/11/all, 13-06-2020. 
REALA. Nueva Época - N. 14, octubre 2020 - ISSN: 1989-8975 - DOI: https://doi.org/10.24965/reala.i14.10825 - [Págs. 161-179]

TABla 2. MM. Integrales de la Provincia de Cáceres

\begin{tabular}{|c|c|}
\hline Denominación & Municipios asociados \\
\hline $\begin{array}{l}\text { M. I. Sierra } \\
\text { de Montánchez }\end{array}$ & $\begin{array}{l}\text { Albalá; Alcuéscar; Aldea del Cano; Almoharín; Arroyomolinos; Benquerencia; Botija; } \\
\text { Casas de Don Antonio; Montánchez; Plasenzuela; Ruanes; Salvatierra de Santiago; Santa } \\
\text { Ana; Sierra de Fuentes; Torre de Santa María; Torremocha; Torreorgaz; Torrequemada; } \\
\text { Valdefuentes; Valdemorales; Zarza de Montánchez. }\end{array}$ \\
\hline $\begin{array}{l}\text { M. I. Comarca } \\
\text { de Trujillo }\end{array}$ & $\begin{array}{l}\text { Aldea del Obispo, La; Conquista de la Sierra; Cumbre, La; Garciaz; Herguijuela; } \\
\text { Ibahernando; Jaraicejo; Madroñera; Puerto de Santa Cruz; Robledillo de Trujillo; Santa Cruz } \\
\text { de la Sierra; Santa Marta de Magasca; Torrecillas de la Tiesa; Trujillo. }\end{array}$ \\
\hline M. Tajo-Salor & $\begin{array}{l}\text { Alcántara; Aliseda; Arroyo de la Luz; Brozas; Casar de Cáceres; Garrovillas de Alconétar; } \\
\text { Hinojal; Malpartida de Cáceres; Mata de Alcántara; Monroy; Navas del Madroño; Piedras } \\
\text { Albas; Santiago del Campo; Talaván; Villa del Rey. }\end{array}$ \\
\hline $\begin{array}{l}\text { M. I. Rivera } \\
\text { de Fresnedosa }\end{array}$ & $\begin{array}{l}\text { Acehúche; Cachorrilla; Casas de Don Gómez; Casillas de Coria; Ceclavín; Holguera; } \\
\text { Pescueza; Portaje; Portezuelo; Riolobos; Torrejoncillo; Zarza la Mayor. }\end{array}$ \\
\hline $\begin{array}{l}\text { M. I. Sierra de } \\
\text { San Pedro }\end{array}$ & $\begin{array}{l}\text { Carbajo; Cedillo; Herrera de Alcántara; Herreruela; Membrío; Salorino; San Vicente de } \\
\text { Alcántara; Santiago de Alcántara; Valencia de Alcántara. }\end{array}$ \\
\hline $\begin{array}{l}\text { M. I. Trasierra-Tierra } \\
\text { de Granadilla }\end{array}$ & $\begin{array}{l}\text { Ahigal; Cabezabellosa; Cerezo; Granja, La; Guijo de Granadilla; Jarilla; Marchagaz; } \\
\text { Mohedas de Granadilla; Oliva de Plasencia; Palomero; Pesga, La; Santa Cruz de Paniagua; } \\
\text { Santibáñez el Bajo; Villar de Plasencia; Zarza de Granadilla. }\end{array}$ \\
\hline $\begin{array}{l}\text { M. I. Comarca } \\
\text { de Las Hurdes }\end{array}$ & $\begin{array}{l}\text { Caminomorisco; Casar de Palomero; Casares de las Hurdes; Ladrillar; Nuñomoral; } \\
\text { Pinofranqueado. }\end{array}$ \\
\hline $\begin{array}{l}\text { M. I. de Municipios } \\
\text { de Sierra de Gata }\end{array}$ & $\begin{array}{l}\text { Acebo; Cadalso; Cilleros; Descargamaría; Eljas; Gata; Hernán-Pérez; Hoyos; Perales del } \\
\text { Puerto; Robledillo de Gata; San Martín de Trevejo; Santibáñez el Alto; Torre de Don Miguel; } \\
\text { Torrecilla de los Ángeles; Valverde del Fresno; Vegaviana; Villamiel; Villanueva de la Sierra; } \\
\text { Villasbuenas de Gata. }\end{array}$ \\
\hline $\begin{array}{l}\text { M. Valle } \\
\text { del Ambroz }\end{array}$ & $\begin{array}{l}\text { Abadía; Aldeanueva del Camino; Baños de Montemayor; Casas del Monte; Garganta, La; } \\
\text { Gargantilla; Hervás; Segura de Toro. }\end{array}$ \\
\hline $\begin{array}{l}\text { M. del Valle } \\
\text { del Jerte }\end{array}$ & $\begin{array}{l}\text { Barrado; Cabezuela del Valle; Cabrero; Casas del Castañar; Jerte; Navaconcejo; Piornal; } \\
\text { Rebollar; Tornavacas; Torno, El; Valdastillas. }\end{array}$ \\
\hline $\begin{array}{l}\text { Mancomunidad } \\
\text { Intermunicipal } \\
\text { de la Vera }\end{array}$ & $\begin{array}{l}\text { Aldeanueva de la Vera; Arroyomolinos de la Vera; Collado de la Vera; Cuacos de Yuste; } \\
\text { Garganta la Olla; Gargüera; Guijo de Santa Bárbara; Jarandilla de la Vera; Jaraíz de la } \\
\text { Vera; Losar de la Vera; Madrigal de la Vera; Pasarón de la Vera; Robledillo de la Vera; } \\
\text { Talaveruela de la Vera; Tejeda de Tiétar; Torremenga; Valverde de la Vera; Viandar de la } \\
\text { Vera; Villanueva de la Vera. }\end{array}$ \\
\hline $\begin{array}{l}\text { M. I. de Municipios } \\
\text { del Valle del Alagón }\end{array}$ & $\begin{array}{l}\text { Aceituna; Alagón del Río; Aldehuela de Jerte; Calzadilla; Carcaboso; Galisteo; Guijo } \\
\text { de Coria; Guijo de Galisteo; Huélaga; Montehermoso; Morcillo; Pozuelo de Zarzón; } \\
\text { Valdeobispo; Villa del Campo. }\end{array}$ \\
\hline $\begin{array}{l}\text { M. de Municipios } \\
\text { Riberos del Tajo }\end{array}$ & $\begin{array}{l}\text { Casas de Millán; Cañaveral; Malpartida de Plasencia; Mirabel; Pedroso de Acim; Serradilla; } \\
\text { Torrejón el Rubio. }\end{array}$ \\
\hline $\begin{array}{l}\text { M. I. de Municipios } \\
\text { del Campo Arañuelo }\end{array}$ & $\begin{array}{l}\text { Belvís de Monroy; Berrocalejo; Bohonal de Ibor; Casas de Miravete; Casatejada; Gordo, El; } \\
\text { Higuera; Majadas; Mesas de Ibor; Millanes; Peraleda de la Mata; Romangordo; Rosalejo; } \\
\text { Saucedilla; Serrejón; Talayuela; Tiétar; Toril; Valdecañas de Tajo; Valdehúncar. }\end{array}$ \\
\hline $\begin{array}{l}\text { M. I. de Villuercas- } \\
\text { Ibores-Jara }\end{array}$ & $\begin{array}{l}\text { Aldeacentenera; Alía; Berzocana; Campillo de Deleitosa; Carrascalejo; Castañar de Ibor; } \\
\text { Cañamero; Deleitosa; Fresnedoso de Ibor; Garvín; Guadalupe; Logrosán; Navalvillar de } \\
\text { Ibor; Navezuelas; Peraleda de San Román; Robledollano; Valdelacasa de Tajo; Villar del } \\
\text { Pedroso. }\end{array}$ \\
\hline $\begin{array}{l}\text { Mancomunidad } \\
\text { de Municipios } \\
\text { «Zona Centro» }\end{array}$ & Abertura; Alcollarín; Campo Lugar; Escurial; Madrigalejo; Miajadas; Villamesías; Zorita. \\
\hline
\end{tabular}


La excepción a esta regla la encontramos en las capitales de provincia (Badajoz y Cáceres), en la capital autonómica (Mérida) y en la ciudad de Plasencia. Son también excepción, pero sólo a razón de la calificación de «Integral», los Municipios de Don Benito y Villanueva de la Serena que tienen conformada su propia Mancomunidad de servicios en común pero donde no participan otros Municipios. Finalmente, son excepción a esta estrategia los Municipios de Navalmoral de la Mata ${ }^{15}$, Almaraz ${ }^{16}$ y Almendralejo ${ }^{17}$, teniendo en común el haber formado parte de una Mancomunidad Integral y, posteriormente, haber instando su salida del grupo de manera más o menos azarosa.

Singularidades aparte, según datos de 2020 del Registro de Entidades Locales, de los 388 Municipios que constan en Extremadura más del $90 \%$ siguen estando mancomunados. Por lo tanto, la relación de entidades enumerada pone de manifiesto que la gran mayoría de los Municipios extremeños forman parte de una Mancomunidad Integral.

\section{TRAYECTORIA DE LA LEY 17/2010, DE 22 DE DICIEMBRE, DE MANCOMUNIDADES Y ENTIDADES LOCALES MENORES DE EXTREMADURA}

\subsection{Antecedentes normativos}

El empeño del Gobierno extremeño en el fenómeno asociativo municipal y la confianza hacia la institución mancomunada -en sintonía con otras Comunidades autónomas-, encuentra su embrión normativo en el Decreto 39/1989, de 9 de mayo, por el que se regula la concesión de subvenciones y ayudas para el fomento de Mancomunidades de Municipios. Este primer texto será derogado con el Decreto 58/1998, de 5 de mayo, por el que se establece un régimen de ayudas para el desarrollo institucional de las Mancomunidades de Municipios en Extremadura. En el preámbulo de ambas normas se reconoce la atención preferente que presta la Junta de Extremadura hacia los Municipios mancomunados. En un primer momento para incentivar la creación de estas asociaciones como cauce para la prestación de servicios obligatorios y ejecución de obras; y en un segundo momento para estimular su desarrollo y consolidar su posición referente en la estructura diseñada desde la administración autonómica.

Del régimen de ayudas a través de diferentes líneas de subvención, se pasó a la creación de un fondo finalista. En esta fase se suceden varios decretos, así: Decreto 56/2002, de 14 de mayo, por el que se establece un fondo de cooperación para las Mancomunidades de Municipios en Extremadura; Decreto 196/2004, de 29 de diciembre, y el Decreto 147/2005, de 5 de junio, por el que se establece un fondo de cooperación para las Mancomunidades de Municipios en Extremadura. En este grupo de normas se avanza en los objetivos marcados, concretamente, se apuesta por potenciar mediante financiación aquellas Mancomunidades que prestan mayor número de servicios, mediante gestión directa y con personal propio, incluyendo funcionarios con habilitación de carácter nacional. Un fondo específico y permanente para dotar de recursos económicos aquellas Mancomunidades que aceptan las directrices marcadas por el gobierno regional.

Un nuevo hito lo marca el Decreto 74/2008, de 25 de abril, por el que se establece un fondo de cooperación para las Mancomunidades Integrales de Municipios de Extremadura. En esta norma, ya derogada ${ }^{18}$, aparece recogida la primera definición legal ${ }^{19}$ de «Mancomunidad Integral». Además, se determinan los requisitos materiales y formales que deben reunir estas agrupaciones para, en tal caso, poder acceder a

15 https://www.elperiodicoextremadura.com/noticias/provinciacaceres/raul-medina-tratara-reforzar-mancomunidad-nueva-etapa 1187079.html, 13-05-2020.

16 https://www.hoy.es/extremadura/201608/12/almaraz-deja-mancomunidad-campo-20160812002611-v.html, 13-05-2020.

17 https://www.hoy.es/almendralejo/almendralejo-pagara-94000-20190315002245-ntvo.html, 13-05-2020.

18 Derogado por disposición derogatoria única del Decreto 118/2012, de 29 de junio, por el que se regulan las bases para distribución del fondo de cooperación para las Mancomunidades Integrales de Municipios de Extremadura.

19 Art. 1.3. «Se consideran Mancomunidades Integrales aquellas que determinen expresamente en sus Estatutos que asumen, entre sus fines, la gestión mancomunada de los intereses generales municipales de su territorio así como el fomento del desarrollo local del mismo; posean plantilla de personal propio al servicio de la Mancomunidad con dedicación plena a la misma y en las que, además, concurran los siguientes requisitos formales y materiales:

a) Requisitos materiales:

a.1. Que la totalidad de los términos de los Municipios que la integran se incluyan en un ámbito geográfico homogéneo y continuo.

a.2. Que la suma de las poblaciones de los Municipios integrantes de la Mancomunidad alcance una cifra de al menos 9.000 habitantes, según los datos de población aprobados por el Instituto Nacional de Estadística.

a.3. Que la Mancomunidad esté formada por un mínimo de siete Municipios que no formen parte de otra mancomunidad que solicite su declaración como integral. 
financiación extraordinaria a través de las órdenes de ayudas y subvenciones que se adscriban anualmente al denominado "Fondo de cooperación para las Mancomunidades Integrales de Municipios de Extremadura", formado no sólo por aportaciones de los presupuestos autonómicos sino también de las dos Diputaciones provinciales que conforman la región. Obsérvese que la finalidad del fondo queda restringida y excluye aquellas Mancomunidades que no consiguen la calificación de «Integral». Aunque el decreto ha sufrido modificaciones, este fondo se crea con vocación de permanencia en los presupuestos regionales y hasta la fecha sigue vigente y adscrito a la misma finalidad ${ }^{20}$.

\subsection{El espaldarazo legislativo}

La articulación del territorio auspiciada por la Junta de Extremadura durante décadas quedó finalmente refrendada en la citada Ley 17/2010, de 22 de diciembre, de Mancomunidades y Entidades locales menores de Extremadura (LMELME).

En lo que se refiere a técnica legislativa, podemos apuntar dos observaciones preliminares. La primera, la singularidad de aprobar una ley específica para dos tipos de instituciones locales sin existir un texto autonómico previo que regule el régimen local con carácter general; esta anomalía es reconocida por el legislador en la exposición de motivos ${ }^{21}$ y defiende que la LMELME es un primer paso para un futuro régimen normativo singularizado para la Administración local extremeña. Peculiar forma de empezar la casa por el tejado, no obstante y transcurridos diez años, la región continúa sin texto autonómico para el régimen local. La segunda anomalía es la combinación en un mismo texto de entidades tan dispares, así, se regulan conjuntamente las Mancomunidades -entidad supramunicipal- y las entidades locales menores -entidad inframunicipal- (en adelante, EELLMM). Llamativamente, la propia exposición de motivos también reconoce esta rara técnica al afirmar que la unión de ambas materias «responde más a razones de oportunidad que de cohesión de ambos regímenes regulatorios».

Pasamos al análisis de las principales directrices de la estrategia plasmadas en esta ley, haciendo un repaso sucinto al contenido de los diez capítulos siguiendo la estructura del título I dedicado a las MM. Integrales, a saber:

\section{Capítulo I. Disposiciones generales}

Este primer bloque se articula especialmente sobre la base de tres premisas. En primer lugar, reiterar la voluntariedad en la génesis de estas entidades de carácter no territorial como expresión de un derecho asociativo de los Municipios y de las EELLMM. En segundo lugar, la naturaleza jurídica de las Mancomunidades y la singularidad que distingue las calificadas como Integrales del resto de Mancomunidades. En tercer lugar, las potestades y prerrogativas con que cuentan para el cumplimiento de sus fines. En síntesis, se trata de un pequeño texto refundido de las disposiciones básicas del régimen local para las Mancomunidades, pero destacando la necesidad de estatutos propios como marco necesario de concreción.

a.4. Que la Mancomunidad preste efectivamente, mediante gestión directa o a través de consorcio de la entidad local, al menos a la mitad de los Municipios o entidades locales menores integrados en ella, servicios en un número de áreas no inferior a cinco de las que se citan a continuación: 1 . Área de sostenibilidad medioambiental, gestión de residuos sólidos urbanos y ciclo del agua; 2 . Área de vigilancia, seguridad, guardería rural y policía; 3. Área de sanidad y bienestar social; 4 . Área de cultura, educación y deportiva; 5 . Área de desarrollo local; 6 . Área de urbanismo, vivienda y ordenación del territorio; 7 . Área de infraestructuras, dotaciones y equipamientos; 8. Área de participación ciudadana, igualdad, información y comunicación.

b) Requisitos formales: La calificación de Mancomunidad Integral se obtendrá mediante Resolución expresa de la Consejería competente en materia de Administración Local, previa solicitud de la entidad interesada y constatación por la Administración Autonómica del cumplimiento de los requisitos antes mencionados. Asimismo la Consejería podrá, mediante Resolución expresa, proceder a descalificar de oficio a una Mancomunidad Integral en el supuesto de que hayan cambiado las circunstancias sobre el cumplimiento de los requisitos que sirvieron para proceder a su calificación como integral o que algunos de sus Municipios formen parte de otra mancomunidad declarada integral.».

20 Actualmente queda regulado en el Decreto 37/2018, de 3 de abril, por el que se regulan las bases para la distribución del Fondo de Cooperación para las Mancomunidades Integrales de Municipios de Extremadura.

21 «Finalmente, el enfoque de la ley no debe perder de vista la interesante posibilidad que representa para la Comunidad Autónoma de Extremadura disponer de una regulación específica en materia de Gobierno y Administración Local, que potencie y singularice el funcionamiento y la labor que en la región, por sus características poblacionales y geográficas, desarrollan todas las entidades locales. En esta idea, la presente ley se configura como un primer paso legislativo que aborda la cuestión, con la mirada puesta en un camino más largo que, de forma coordinada, establezca los instrumentos que permitan un régimen normativo singularizado para nuestra Administración Local.». 


\section{Capítulo II. Creación y Constitución}

De manera pormenorizada este capítulo estipula el procedimiento para la creación y constitución de una Mancomunidad en Extremadura. Así, enumerando de forma sumaria, se inicia con un acuerdo expresivo de la voluntad inicial de mancomunarse por cada uno de los Municipios o EELLMM interesadas (mayoría simple del Pleno y, en su caso, de la Junta Vecinal). Seguidamente se constituye una comisión promotora con los Alcaldes y Alcaldes pedáneos, que llevará a cabo los trabajos de redacción del proyecto de estatutos y el impulso de los trámites. Concluidos los trabajos de la Comisión, se constituirá una Asamblea (un representante por cada entidad local moderados por una Mesa de edad) para la aprobación provisional de los estatutos. Tras la Asamblea y en el plazo máximo de tres meses, las entidades locales interesadas deberán aprobar la creación de la nueva Mancomunidad, su incorporación a ella y la ratificación de los estatutos propuestos por la Asamblea (mayoría absoluta del número legal del Pleno y, en su caso, de la Junta Vecinal). Después del acuerdo de todas las entidades, la aprobación provisional de los estatutos se someterá a información pública por un mes desde su publicación en el Diario Oficial de Extremadura; asimismo se remitirá a las Diputaciones Provinciales interesadas y a la Consejería del ramo para su informe (con silencio positivo). Finalizado el trámite y, en su caso, resueltas las posibles alegaciones con informe de la Comisión y aprobación definitiva por la Asamblea y los órganos de gobierno de las entidades interesadas, se publicará de nuevo en el DOE y se inscribirá en los Registros de Entidades Locales, estatal y autonómico. Tras la aprobación definitiva, se convocará una Asamblea constitutiva de la Mancomunidad en el plazo de treinta días naturales, donde se procederá a la elección del Presidente, Vicepresidente o Vicepresidentes de la Mancomunidad y a la designación del resto de los miembros de la Junta de Gobierno.

\section{Capítulo III. Calificación y descalificación como Integral de las Mancomunidades}

Este apartado recoge el procedimiento para obtener o perder la calificación de «Integral». Se trata de un reconocimiento para las Mancomunidades, de nueva creación o ya constituidas, que otorgará la Consejería competente siempre y cuando se acredite el cumplimiento de un conjunto de requisitos que podemos clasificarlos en dos grupos en función de su grado de concreción:

a) Requisitos determinados reglamentariamente.

- El sumatorio de los padrones de las entidades integrantes debe alcanzar la cifra de población estipulada reglamentariamente. Actualmente, el número está fijada en 6.000 habitantes, de conformidad con el art. 1.3.a) del Decreto 37/2018, de 3 de abril, por el que se regulan las bases para la distribución del Fondo de Cooperación para las Mancomunidades Integrales de Municipios de Extremadura.

- Número mínimo de miembros que no formen parte de otra Mancomunidad Integral. Conlleva una cláusula de exclusividad, no obstante se permite que una entidad local cambie de Mancomunidad Integral siempre y cuando se separe previamente de la anterior. Al igual que el criterio del padrón, el citado Decreto 37/2018 establece un mínimo de seis entidades locales.

b) Requisitos indeterminados.

- Contar con plantilla de personal propio con dedicación plena. Cabe apuntar que no se prevé número mínimo por lo que con un empleado se podría cubrir el requisito.

- Ámbito geográfico continuo para los términos de todas las entidades integrantes. Existe excepciones a esta norma para el caso de las EELLMM cuyo Municipio matriz no forme parte de la Mancomunidad; para aquellos Municipios cuyo término esté dentro de otro término (entendemos que rodeado); y cuando «tengan una delimitación geográfica particular». Observamos que las excepciones son tantas que el cumplimiento de este requisito se modula de forma flexible.

- Identidad cultural, geográfica, económica o histórica común y homogénea. No se aporta mayor concreción al respecto y, en síntesis, cabria cualquier motivación.

- Prestar servicios de, al menos, tres áreas competenciales ${ }^{22}$ para la mitad de las entidades integrantes o un número inferior siempre que aglutinen a la mitad de la población de la Mancomunidad.

22 La versión vigente del art. 19.2.g) LMELME recoge las siguientes áreas: 1. Urbanismo; 2. Abastecimiento de agua potable a domicilio y evacuación y tratamiento de aguas residuales; 3. Infraestructura viaria y otros equipamientos; 4 . Protección civil, prevención y extinción de incendios; 5 . Información y promoción turística; 6 . Protección de la salubridad pública y sostenibilidad medioambiental; 
A propósito de esta obligación, debemos apuntar que la técnica jurídica de conjugar los términos «servicios» y «áreas» aboca a la indeterminación conceptual, máxime cuando tampoco se ha desarrollado reglamentariamente. Al respecto, debemos insistir en el hecho de que no existe ley autonómica que regule el régimen local y que la legislación básica estatal del régimen local utiliza las expresiones "competencias», «materias» y "servicios». Haciendo una interpretación extensiva, podríamos equiparar «áreas» con «materias» aunque no coinciden en la relación enumerada.

En definitiva, este despliegue terminológico sin una norma de referencia a la que acudir para conocer el desglose de dichas áreas o la correlación servicios-áreas, plantea en la práctica una relación de servicios de encaje o alcance dudoso y, lo que es más importante, problemas de seguridad jurídica para las propias entidades mancomunadas a la hora de acordar los servicios que puedan contar para obtener la calificación de «integrales».

Si observamos el conjunto de requisitos exigidos para obtener tal calificación, observamos una preeminencia de condiciones indeterminadas que restan objetividad al proceso y dejan un amplio margen de discrecionalidad a la Administración autonómica. Este dato no es baladí si tenemos en cuenta la mejor posición que reciben aquellas Mancomunidades diferenciadas como «Integrales» y, viceversa, la pérdida de la condición como correctivo para los supuestos de incumplimiento grave de las obligaciones asumidas. Haciendo una lectura en conjunto -LMELME más la reglamentación previa y posterior- la consecuencia inmediata anexa a la obtención de la calificación es el acceso a un grupo de recursos financieros exclusivos que, por descalificación, perderán la posibilidad de conseguir.

\section{Capítulo IV. Gobierno y régimen de funcionamiento de las Mancomunidades}

El gobierno y la administración de las Mancomunidades requiere la aprobación de unos estatutos y de sus reglamentos orgánicos, pero el margen de autonomía es estrecho si atendemos a los contenidos mínimos que, en todo caso, deben recoger y que, en este capítulo se desarrollan de manera profusa. No existe ninguna previsión particular para las MM. Integrales.

En lo que se refiere a los órganos de gobierno se opta por la estructura típica de las entidades asociativas. Sobre esta base, los órganos mínimos necesarios se dividen en colegiados y unipersonales. Los primeros son la Asamblea, la Junta de Gobierno y la Comisión Especial de Cuentas ${ }^{23}$; y los segundos la Presidencia y la Vicepresidencia. Como órganos complementarios se prevé la posibilidad de crear comisiones informativas.

Por lo que se refiere a los miembros, podemos destacar dos particularidades. Por un lado, para formar parte de cualquier órgano se requiere la condición de concejal o de representante en la Junta Vecinal. Por otro, la pérdida de tal condición es causa de cese como miembro del órgano aunque permanecerán en funciones para cuestiones de administración ordinaria de la Mancomunidad hasta tanto el Municipio o entidad local menor nombren a su nuevo representante.

\section{Capítulo V. Personal al servicio de las Mancomunidades}

En síntesis, el régimen jurídico aplicable al personal al servicio de la Mancomunidad es el propio de las entidades locales que la integran sin perjuicio de las concreciones que se recojan en los estatutos y la reglamentación interna. En lo que se refiere a las funciones públicas necesarias son las propias de los habilitados nacionales, pero se contempla excepciones a dicha necesidad; por una parte, la posibilidad de agruparse con otras entidades para el mantenimiento en común del puesto -previo acuerdo expreso- y, por otra, la exención de tal obligación cuando el volumen de servicios o recursos no sea suficiente para mantener dichos puestos -mediante reconocimiento de la Comunidad Autónoma-.

Finalmente, recordemos que para el caso de las MM. Integrales, el art. 19.2.b) LMELME establece como requisito poseer plantilla de personal propio con dedicación plena.

7. Deporte y ocupación del tiempo libre; 8. Cultura; 9. Participación ciudadana en el uso de las TICS; 10. Evaluación e información de situaciones de necesidad social y atención inmediata de personas en situación de riesgo de exclusión social.

23 Órgano necesario en las entidades locales atendiendo a lo establecido en el art. 116 LRBRL. 


\section{Capítulo VI. Recursos y régimen económico}

La hacienda de estas entidades se constituye con los recursos financieros y tributarios (excluidos los impuestos) que les reconoce la Real Decreto Legislativo 2/2004, de 5 de marzo, por el que se aprueba el texto refundido de la Ley Reguladora de las Haciendas Locales. Sobre esta base, la norma autonómica enumera las potestades y tributos que, en su caso, podrán exigir previa la correspondiente ordenanza fiscal, así como el régimen presupuestario y la posibilidad de concertar operaciones de crédito.

Cabe destacar la regulación que se prevé para las aportaciones económicas comprometidas por los miembros y, concretamente, las herramientas articuladas para el caso de su impago (art. 50). Por una parte, la Mancomunidad ostentará las prerrogativas establecidas legalmente para la hacienda del Estado, y actuará, en su caso, conforme a los procedimientos administrativos correspondientes. Por otra parte, las aportaciones vencidas, líquidas y exigibles podrán ser objeto de retención, una vez transcurrido el plazo de pago previsto en los estatutos y previo requerimiento al miembro afectado, respecto de las que tengan pendientes de percibir de la Comunidad Autónoma de Extremadura o de las Diputaciones Provinciales.

Las especificidades para las MM. Integrales en materia económica se prevén para los apoyos económicos que pueden recibir desde otras Administraciones. Al respecto, la norma autonómica expresa la posibilidad en el desarrollo reglamentario de priorizarlas en el beneficio de recursos económicos adscritos a determinados fondos que, además, podrán ser condicionados. Más concretamente, en párrafo específico, se recoge la institución del Fondo Regional de Cooperación para Mancomunidades Integrales con cuantía anual a través de la Ley de Presupuestos de Extremadura; Fondo que, tal como se indicó en los antecedentes, ya estaba creado y regulado reglamentariamente.

\section{Capítulo VII. Incorporación y separación de Municipios y EELLMM}

La ley autonómica prevé la posibilidad de que otros Municipios o EELLMM puedan incorporarse al ente asociativo con posterioridad a su creación. En tal sentido, concreta el procedimiento y el contenido del acuerdo necesario para la adhesión del nuevo miembro. No obstante, como requisito específico, se exige con carácter previo a la incorporación la liquidación y el cumplimiento total de los compromisos con otras Mancomunidades a la que ya estuvieran asociados salvo que hubieran obtenido autorización expresa de sus máximos órganos de gobierno.

En materia de disociación se contempla tanto la posibilidad voluntaria como la obligatoria, requiriendo ambas acciones acuerdo previo por mayoría absoluta de la entidad promotora de la separación y el cumplimiento de los compromisos económicos. Dicho lo anterior, procede detenerse en la causa establecida para la separación obligatoria, a saber, haber «incumplido grave y reiteradamente las obligaciones establecidas en la normativa vigente o en los estatutos para con ella». Estamos ante una motivación de carácter punitivo que, sin embargo, se articula a través de conceptos jurídicos indeterminados que, a lo sumo, podrán ser concretados por vía de estatutos. A nuestro entender, la aparente gravedad de la causa legal que motivaría la separación queda atemperada por la indefinición en la redacción y, salvo que los estatutos detallen los supuestos de incumplimiento grave y de reiteración, aboca al uso residual de esta posibilidad en la práctica.

\section{Capítulo VIII. Relaciones interadministrativas}

Sobre las bases del régimen local, la norma autonómica opta por los convenios de cooperación como instrumentos para las relaciones interadministrativas de las Mancomunidades, ya sean con otras Entidades locales ya sean con el resto de administraciones. Ahora bien, se restringe esta posibilidad para las MM. Integrales ya que no podrán acudir a este tipo de acuerdos cuando tengan por objeto la prestación de la mayoría de los servicios que haya asumido, o cuando afecten a su respectiva autonomía.

Fiel reflejo en la ley de la estrategia que persigue el legislador autonómico son las peculiaridades que se establecen para las MM. Integrales en su relación con la administración autonómica. Por una parte, se estipula un canal de comunicación bidireccional ya que tanto la Administración autonómica como las Mancomunidades tienen que facilitarse información, constituyendo un deber la remisión de extracto comprensivo de los actos y acuerdos adoptados por los órganos de las entidades asociativas. Por otra parte se regula la coordinación del ejercicio de las competencias de las MM. Integrales mediante planes sectoriales donde la Junta de Extremadura fijará los objetivos y prioridades de la acción pública. 
En línea con lo anterior y de manera expresa, se recoge una sección dedicada a medias para el fomento y apoyo de las MM. Integrales. Concretamente se prevén acciones de especial asesoramiento; la posibilidad de concesión de ayudas autonómicas para las inversiones necesarias para el proceso de constitución y para gastos de funcionamiento; calificación como «prioritarias» las obras y servicios propuestos por las MM Integrales en los plantes de inversión provinciales y autonómicos; incluso la delegación de la ejecución de obras y servicios -acompañadas de la financiación necesaria-.

\section{Capítulos IX y X. Modificación de estatutos; y Disolución de Mancomunidades}

En estos capítulos se articulan las previsiones para los supuestos de modificación y disolución, con un procedimiento similar al dispuesto para la creación. No se recoge ninguna especificidad para las MM. Integrales.

Independientemente de las fallas apuntadas en materia de técnica legislativa, el Legislador autonómico plasma su estrategia de reorganización territorial priorizando el asociacionismo como medio indirecto para solventar las disfunciones del inframunicipalismo (Estrategia del Sur). Ahora bien, aunque las referencias a la voluntariedad y a la autonomía de las entidades locales son una constante y tienen su expresión en las referencias a los estatutos y reglamentos orgánicos, este mantra queda teledirigido si observamos el profuso desarrollo de muchos aspectos en la ley, lo que deja en la práctica un margen de autonomía muy estrecho. Más todavía si atendemos a la regulación de las MM. Integrales, tipología que se potencia sobremanera si tenemos en cuenta los beneficios financieros que conllevan tal calificación.

\subsection{Hitos posteriores más significativos}

Diez años de vigencia podrían parecer un trayecto no excesivamente largo si comparamos con otras normas autonómicas. No obstante, en lo que se refiere a la materia que nos ocupa podemos destacar algunos hitos significativos en este tiempo de coexistencia con el resto del ordenamiento jurídico.

\section{a) Decreto-ley 3/2014, de 10 de junio, por el que se modifica la Ley 17/2010, de 22 de diciembre, de Mancomunidades y Entidades Locales Menores de Extremadura ${ }^{24}$}

Tras un cómodo periodo donde la LMELME se consideró el refrendo perfecto a toda una estrategia político-territorial abonada ideológicamente durante años y regada financieramente de manera preferente por los gobiernos extremeños, irrumpieron los efectos de la crisis financiera iniciada en 2008. La recesión económica expuso las debilidades del sobreendeudamiento de las administraciones públicas y, particularmente, de la administración local. Lo anterior llevó al escrutinio general de las estructuras administrativas -competencias y financiación- y a la consecuente puesta en marcha de diferentes programas de reforma y ajustes presupuestarios en la Administración a todos los niveles.

Las exigencias de la Unión Europea, a raíz de la coyuntura económica negativa, forzaron al Gobierno central a promulgar reformas legislativas encaminadas a conseguir la estabilidad presupuestaria y la sostenibilidad financiera ${ }^{25}$. Concretamente en el ámbito local se aprobaron modificaciones en la legislación básica de régimen local mediante la aprobación de la Ley 27/2013, de 27 de diciembre, de racionalización y sostenibilidad de la Administración Local (en adelante, LRSAL). En dicha norma estatal se expone motivadamente la necesidad de examinar el conjunto de entidades instrumentales que configuraban el sector público local, así como la reordenación de sus órganos de gobierno y estructuras. En este sentido, destaca como objetivo esencial reducir la dimensión del sector público local, lo que implicaba la necesidad de controlar la actividad y racionalizar su organización de, entre otras, las Mancomunidades hacia la sostenibilidad (Boix, 2014: 103). Finalmente, con el propósito de mejorar la eficiencia y reducir el gasto público, se establece un plazo de seis meses para el saneamiento de las entidades deficitarias so pena de disolución (Zamora, 2013: 146). En igual sentido se manifestó el Consejo de Estado, que recuerda la condición no necesaria o contingente de estas Entidades locales (2013: 43), y también el Ministerio de Hacienda y Administraciones Públicas (2014: 9).

24 Publicado en DOE núm. 111, de 11-06-2014, y BOE núm. 159 de 01-07-2014.

25 Desde el año 2011 en cumplimiento de los compromisos adquiridos en materia financiera, anualmente se remiten al Consejo de Ministros de la Unión Europea y a la Comisión Europea un Programa Nacional de Reformas junto con el programa de estabilidad de España. 
Así las cosas, la reforma de 2013 afectó directamente a las Mancomunidades a través de la disposición transitoria undécima LRSAL, restringiendo su empleabilidad y limitando su campo de acción para, entre otros objetivos, evitar situaciones de concurrencia competencial entre las distintas Administraciones Públicas, duplicidad en la prestación de servicios, o que dichos servicios fueran prestados sin tener habilitación o sin contar con recursos adecuados para ello. De manera taxativa la LRSAL orienta las competencias de estas entidades exclusivamente a la realización de obras y a la prestación de los servicios públicos que sean necesarios para que los Municipios puedan ejercer las competencias que éstos tienen reconocidas en los arts. 25 y 26 LRBRL -una vez modificados y limitados por virtud de la misma LRSAL-.

En virtud de las limitaciones competenciales acuñadas por el Legislador estatal, el Legislador extremeño tuvo que aprobar la reforma urgente de la LMELME por vía de Decreto-ley a fin de evitar la desaparición de algunas MM. Integrales que pudieran incurrir en las circunstancias de disolución estipuladas en la citada disposición transitoria undécima. En la exposición de motivos del Decreto-ley 3/2014 el legislador autonómico - de manera velada- expresa su disconformidad con las medidas estatales; al respecto, la restricción del marco competencial a las Mancomunidades y su necesaria revisión estatutaria so pena de disolución, pone en riesgo la articulación del territorio regional a través de MM. Integrales porque:

«tras la entrada en vigor de la Ley de racionalización y sostenibilidad de la Administración Local, los requisitos para obtener la calificación de Integral reflejados en la legislación extremeña pudieran entrar en contraposición con el régimen competencial que para las Mancomunidades de Municipios se recogen en la nueva regulación estatal, mucho más limitado que el anterior, y, en consecuencia, verse afectadas en su calificación aplicando las actuales exigencias de nuestra Ley. Y es que la determinación del número mínimo de cinco áreas, para cuya modificación no está habilitado el Consejo de Gobierno, compromete la calificación de Integral obtenida por muchas Mancomunidades y su derecho a la percepción de los créditos correspondientes al Fondo de Cooperación».

Como respuesta ante este cambio en el régimen jurídico de las Mancomunidades, y a fin de salvaguardar la estrategia regional para el territorio, el Legislador autonómica afina el objeto de estas entidades, por una parte, suprimiendo la clausula competencial genérica recogida en el art. 19.2.a) LMELME y, por otra, rebajando las exigencias recogidas en el art. 19 LMELME para ser calificadas como «Integrales». Concretamente, las Mancomunidades podrán mantener/obtener la calificación siempre que presten servicios en al menos tres áreas competenciales y que dichos servicios cubran a la mitad de sus miembros o a un número inferior que represente al menos a la mitad de la población. En definitiva, se reduce el número de áreas competenciales pasando de cinco a tres, y se introduce el criterio poblacional para flexibilizar el requisito del número mínimo de entidades perceptoras de los servicios.

\section{b) Ley 3/2019, de 22 de enero, de garantía de la autonomía municipal de Extremadura}

Las citadas reformas impulsadas por el Gobierno de la Nación a cuenta de la crisis de 2008 -con marcado carácter restrictivo frente a planteamientos expansivos de la autonomía local- tuvieron su contrapunto en los numerosos recursos y conflictos promovidos contra la LRSAL (una de ellas desde la propia Asamblea de Extremadura y otras por un gran número de Municipios extremeños), prolongando una situación de incertidumbre a la espera de que el Tribunal Constitucional se pronunciase. La respuesta del Tribunal Constitucional fue la estimación parcial pero declarando válidas la mayoría de las reformas impugnadas y, especialmente, dejando intactos los preceptos dedicados a la reforma competencial ${ }^{26}$; en su virtud, unos interpretaron que el marco local quedaba disfuncional y, por contra, otros entendieron que las bases locales reformas eran conforme a derecho.

El Legislador extremeño se posicionó manifestando que el panorama era «confuso» y alegando razones de incomprensión hacia el modelo local redefinido por el Legislador estatal. Sobre esta base argumental se aprueba una ley regional en pro de la autonomía municipal so pretexto de los vacíos de inconstitucionalidad ocasionados en la LRBRL tras los pronunciamientos del TC a cuenta de la LRSAL. En otras palabras,

26 STC 41/2016, de 3 de marzo, sobre recurso interpuesto por la Asamblea de Extremadura, BOE núm. 85, de 8 de abril de 2016; STC 111/2016, de 9 de junio, sobre recurso de inconstitucionalidad interpuesto por el Consejo de Gobierno de la Junta de Andalucía, BOE núm. 170, de 15 de julio de 2016; y STC 168/2016, de 6 de octubre, sobre recursos de inconstitucionalidad interpuesto por el Gobierno del Principado de Asturias, BOE núm. 276, de 15 de noviembre de 2016. 
la Ley extremeña se aprueba como respuesta política para aquietar una supuesta contracción del margen competencial de los Municipios; ahora bien, sigue renunciando en sus planteamientos a construir un texto normativo local extremeño y, además, se olvida de cualquier referencia a las bases del régimen local. No es de extrañar que autores de la talla de CHECA GONZÁLEZ hayan rechazado la valía de esta norma de forma contundente, así: «es una ley banal, inconsistente y perfectamente prescindible, hasta el punto de que lo mejor y más oportuno habría sido, desde luego, que jamás se hubiese promulgado» (Checa, 2019: 574).

No procede aquí entrar en el análisis del contenido de esta norma, aunque si queremos hacer un apunte a propósito de una cuestión que ya hemos comentado con relación a la LMELME. Se trata de la inexactitud en la terminología jurídica relativa al régimen local en Extremadura, el legislador autonómico acuña nuevos conceptos en la redacción de la Ley 3/2019 LGAME pues se expresa en términos de «áreas» (o «materias o ámbitos», art. 15), dentro de éstas se distinguen «competencias» (art. 12) y, a su vez, éstas se concretan en «funciones o facultades» (art. 13). Quizás en el afán por desligarse de las bases del régimen local se desprendió también de la terminología y crea un nuevo vocabulario que -a nuestro entender- sólo suma confusión.

Por lo que aquí interesa, aunque el objeto de la citada ley es apuntalar el margen competencial de la institución municipal, se aprovecha para ratificar la estrategia territorial basada en MM. Integrales. En esta línea se encuadran las referencias en la Ley 3/2019 a la institución mancomunada y, especialmente, a las MM. Integrales. Sobre esta base no hay más allá de una declaración de intenciones en la exposición de motivos y de las referencias obligadas a cuestiones como la posibilidad de prestar servicios a través de entes asociativos (art. 4), o la Mancomunidad como manifestación preferente de la potestad de autoorganización (art. 9).

Nos encontramos, en definitiva, con una norma con vocación de permanencia pero que nace de un contexto claramente coyuntural, pues instituye un elenco de garantías para la autonomía local en clara respuesta a reformas puntuales impulsadas por el Ejecutivo central. A pesar de la intención, es una norma que aborda la institución municipal de forma parcial, y que defiende la autonomía municipal a la par que sigue apostando por las Diputaciones provinciales y por las Mancomunidades como prestadoras de servicios municipales. A nuestro juicio es un contrasentido pues son entidades que existen y sobreviven a causa de la debilidad municipal.

Lo antedicho no impide que ambos hitos normativos, en el 2014 y en el 2019, pongan de manifiesto la continuidad en la estrategia territorial propiciada por los diferentes Gobiernos autonómicos, pues a pesar de haber sido estrechado el margen de maniobra, se continúa apostando por la Mancomunidad Integral como pieza fundamental en la vertebración de servicios y en las relaciones con el resto de administraciones, especialmente la autonómica.

\section{REVISIÓN: PUNTOS PARA UN DEBATE INAPLAZABLE}

La trayectoria normativa de la vertebración local en Extremadura deja una primera reflexión para el debate a cuenta de esta apuesta autonómica por el asociacionismo. A poco que analicemos el esquema de las administraciones que interaccionan en el territorio extremeño, observamos una superpoblación de entidades locales. De esta manera, la vecindad de cada Municipio está obligada a interaccionar de manera permanente no con una sino con tres o cuatro entidades locales diferentes: el Municipio, la Mancomunidad Integral, la Diputación provincial y, en su caso, la entidad local menor. Conjunto de entidades a los que se les pueden sumar otras instituciones creadas para la gestión de servicios específicos como los organismos autónomos, los consorcios, los centros integrales de desarrollo, los grupos de acción local ${ }^{27}$; amén de la administración autonómica y toda su red de institutos y empresas públicos; amén de la administración general del Estado y sus entidades. Pongamos un ejemplo, pensemos en la puesta en marcha de una PYME; de entrada, necesitará pedir licencia de actividad (Municipio), seguramente licencia de obra (que puede depender del servicio técnico de la Mancomunidad Integral o de la Diputación provincial), además de pasar por la entidad gestora del suministro de agua (que puede ser un consorcio, una empresa concesionaria, o una Mancomunidad), de tener que brear con departamentos autonómicos (informes preceptivos en cuestión de medio ambiente, patrimonio,...) o, incluso, un grupo de desarrollo rural (para poder acceder a fondos europeos).

27 Los Grupos de Acción Local o Grupos de Desarrollo Rural son asociaciones sin ánimo de lucro, de ámbito comarcal, donde se integran entidades públicas (Ayuntamientos y Mancomunidades) y privadas (colectivos de jóvenes, asociaciones de mujeres, asociaciones empresariales, sindicatos, etc.) representativas del tejido socioeconómico de la comarca. (definición recogida en www.redex.org). 
En este contexto regional de superpoblación administrativa y, al mismo tiempo, con tendencia constante a la pérdida de población, debemos revisar -serena pero inaplazablemente- qué ventajas supone mantener una estrategia territorial basada en una red de Mancomunidades. Adelantamos que la fórmula mancomunada no ha remediado los problemas asociados al inframunicipalismo, especialmente en lo que a las carencias económicas se refiere. Al respecto exponemos las principales carencias y debilidades que, a nuestro juicio, el modelo asociativo implementado en Extremadura no ha conseguido subsanar:

a) En el ámbito institucional.

A pesar del tiempo transcurrido, las MM. Integrales siguen encontrando dificultades, organizativas y competenciales, para encajar dentro del conjunto de instituciones que conforman la comunidad política local. Así lo entendemos porque esta estrategia se apoya en una estructura administrativa adicional, paralela y con financiación derivada, de tal forma que no pocas veces interfiere con la gestión de otras Administraciones locales, como es el caso de las Diputaciones o, incluso, de los propios Municipios (Jiménez, 2012: 47). En esta circunstancia incide el hecho de que las MM. Integrales no son entidades mono-competenciales sino que están diseñadas para asumir varios servicios en un mínimo de tres áreas competenciales dentro de un extenso abanico, lo que en la práctica multiplica los puntos en común y facilita la presencia de zonas grises donde surgen dudas y se producen fricciones.

En este mismo terreno debemos encuadrar el debate -siempre recurrente, pero sin resolversobre la legitimidad democrática de estas entidades de segundo grado; entidades donde la ciudadanía no interviene directamente en la elección de sus órganos de gobierno, pero donde se gestionan competencias y adoptan decisiones que repercuten altamente sobre los administrados. Del mismo modo, la difícil conjugación de representación política y proporcionalidad municipal hace que, en determinadas ocasiones, se desvirtúe la composición de los órganos de gobierno de estas entidades asociativas. Ambas circunstancias favorecen el alejamiento y el desconocimiento de la ciudadanía hacia este escalón de la administración local llegando, incluso, al rechazo.

La trayectoria extremeña pone de manifestó que muchas de estas entidades tienen problemas recurrentes de gobernabilidad. Podemos apuntar algunas apreciaciones sobre este cuestión. Por una parte, existen ediles municipales que acumulan importante poder fáctico en el ámbito de la Mancomunidad frente al Municipio (Rodríguez, 2006: 119) y, por tal motivo, aprovechan la posición para visualizar su perfil y utilizar estas entidades como lanzaderas hacia la política autonómica. Cuando las injerencias políticas -que suelen ir en paralelo a los problemas económicos- persisten en el seno de las Mancomunidades se puede llegar a la separación de alguno de sus miembros (v. gr:: Municipio de Almaraz), así como a la paralización o a la disolución de la asociación (v. gr.: Mancomunidad Tierra de Barros). Por otra parte, en determinadas ocasiones la gestión política de las Mancomunidades se confunde con la de los entes integrantes, se desdibujan los límites de las decisiones, debilitando la transparencia, dificultando las exigencias en materia de responsabilidad públicas (FDYGL, 2011: 179) y la ausencia de control directo de los ciudadanos (Chinchilla, 2014: 11). Son circunstancias frecuentes donde la mala praxis desprestigia esta vía ante la opinión pública, y con ella arrastra a la institución municipal (López, 2009: 193).

b) En el ámbito administrativo.

Las debilidades institucionales tienen su reflejo en el ámbito administrativo, de tal forma que, tanto la toma de decisiones como la gestión, no se rige exclusivamente por criterios de eficiencia sino que están influidas considerablemente por los conflictos y la rivalidad de intereses entre los diferentes integrantes. Asimismo, muchas de las decisiones requieren la ratificación en dos tiempos, a nivel de entidad municipal y a nivel de Mancomunidad, lo que ralentiza el ritmo. Esta situación ha sido calificada por el Prof. Almeida Cerreda como uno de los principales inconvenientes, porque los problemas de gobernabilidad provocan riesgo de ineficacia (Almeida, 2013: 112). Una clara manifestación de la ralentización de los procedimientos es la falta de adaptación entre las actuaciones acordadas en las políticas mancomunadas y las necesidades reales de la ciudadanía destinataria.

El riesgo de ineficiencia se comprueba a través de dos circunstancias. Por una parte, la duplicidad que en muchas ocasiones se da en cuestión de servicios que se solapan y provocan un exceso de estructuras y recursos humanos destinados a realizar tareas similares. Esta duplicidad administrativa se ha criticado ampliamente de la estrategia asociativa; en concreto, para Francia este problema se denomina «doublon» (Heinelt, 2012: 88). Por otra parte, la ineficiente gestión de recursos económicos reflejada en un aumento de gastos con origen en la expansión del Capítulo 1 
(personal), los costes de transacción para dar cobertura a todas las exigencias de los Municipios y demás entidades asociadas (Arenilla, 2012: 187), y la generalizada ausencia de rendición de cuentas en tiempo y forma (Tribunal de Cuentas, 2009: 30) ${ }^{28}$. En definitiva, más burocracia.

c) En el ámbito de los recursos humanos.

Recordemos que una de las exigencias para obtener la calificación de Integral es contar con plantilla de personal propio con dedicación plena, pero también apuntamos anteriormente que no se exige número mínimo para cubrir tal condición. La realidad de las plantillas actuales muestra que estas entidades también practican la precariedad laboral pues cuentan con un alto porcentaje de trabajadores temporales. Esta inestabilidad en el empleo público se debe a que la existencia de gran parte de los servicios que prestan depende de las convocatorias de ayudas que sacan periódicamente la Comunidad autónoma o la Diputación provincial (v. gr.: entre otros, Programas de Atención a las Familias, Dinamización Deportiva De Extremadura, Oficina de Igualdad y Violencia de Género). Esta circunstancia es reconocida en el Decreto autonómico 37/2018 que regula el Fondo de Cooperación para las MM. Integrales; así, para percibir ayudas por gastos corrientes se tiene que acreditar que el personal de la plantilla esté «desempeñando de forma continuada durante al menos doce meses por la misma persona» (art. 7.3.a) y, además, «no se computará el personal de plantilla cuyos costes de personal sean financiados en más del cincuenta por ciento por la Junta de Extremadura, las Diputaciones Provinciales o cualquier otro organismo, entidad o particular no perteneciente a la Mancomunidad». En definitiva, las Mancomunidades no han contribuido a mejorar la calidad del empleo público porque repiten los vicios de otras entidades locales.

A nuestro entender, el otro flanco débil en materia de recursos humanos en la red extremeña de MM. Integrales es la figura de las gerencias de Mancomunidad. La implantación generalizada de este rol directivo forma parte de la estrategia autonómica desde sus comienzos y se inspira en la regulación de los servicios municipalizados en régimen de gestión directa con órgano especial ${ }^{29}$. Más allá de que su fundamentación es más política que jurídica, debemos plantearnos si tiene sentido mantener esta tipología de puestos. Sin entrar a valorar el buen hacer personal de quienes lo pueden ocupar, lo cierto es que es una figura de difícil encaje en una entidad asociativa de micromunicipios, máxime cuando la presencia de los funcionarios habilitados nacionales es obligada $-\mathrm{y}$ existe en todas las Mancomunidades desde su creación-y la dedicación de los órganos unipersonales de dirección es plena a menudo ${ }^{30}$. Bien es cierto que la financiación de estos puestos viene siendo cubierta por la Comunidad Autónoma -lo que redunda en nuestra opinión sobre la naturaleza política de esta figura-, pero el propio hecho de tener que sufragar el gasto a través del fondo autonómico pone en evidencia la insostenibilidad con los solos recursos de la asociación ${ }^{31}$. Sobre el papel es un órgano directivo con la tarea principal de gestionar y coordinar los recursos humanos y la administración de los distintos servicios prestados desde el ente asociativo; en la práctica, es un contrapunto a las tensiones políticas que puedan existir entre los Municipios integrantes y que, en última instancia, sigue las indicaciones estratégicas de la comunidad autónoma.

d) En el ámbito financiero.

Las MM. Integrales no contribuyen a solucionar las carencias financieras que acompañan al inframunicipalismo. Hacemos nuestro este juicio dictado por el Prof. Fernando ALBI a mediados del siglo pasado, poniendo de manifiesto que:

28 Según datos del Tribunal de Cuentas sólo el $55 \%$ de las Mancomunidades rindió cuentas del ejercicio presupuestario 2017 , y de éstas sólo el $44 \%$ lo hizo en plazo. A pesar de lo bajo de este porcentaje, supone una mejora con relación al de años anteriores que se situaba en torno al $28 \%$; curiosamente, sólo en la rendición de cuentas del año 2013 se alcanzó el $89 \%$ por la advertencia de disolución recogida en la recién aprobada disposición transitoria $4 .^{\mathrm{a}} \mathrm{LRSAL}$.

29 Decreto de 17 de junio de 1955 por el que se aprueba el Reglamento de Servicios de las Corporaciones locales. Art. 71: «Los servicios municipalizados o provincializados en régimen de gestión directa con órgano especial estarán a cargo de un Consejo de Administración y de un Gerente».

30 https://www.hoy.es/v/20111031/regional/presidentes-mancomunidades-apuntan-cobrar-20111031.html, 13-06-2020.

31 La creación y generalización de las gerencias en las MM. Integrales tiene su punto de partida en el año 2004 a través de una serie de convenios de colaboración entre la Consejería de Desarrollo Rural y cada una de las Mancomunidades, redactados ad hoc para la contratación de un gerente. Esta dinámica de convenios se mantuvo hasta que por Decreto 6/2009, de 23 de enero, se modificaba el Decreto 74/2008, de 25 de abril, que regula el fondo de cooperación para las Mancomunidades Integrales de Municipios en Extremadura (DOE, 29-01-2009). A partir de esta fecha, el coste del puesto de Gerente se incluye anualmente entre los gastos cubiertos por el fondo de cooperación para las mancomunidades Integrales ( $v$. g.: art. 5 y Anexo I de la Orden de 16-06-2009 por la que se convocan ayudas del fondo de cooperación para las Mancomunidades Integrales de Municipios en Extremadura, DOE, 19-06-2009). 
«si se trata de asociar varios Municipios pobres, la situación financiera inicial persistirá en el organismo integrador, pues la suma de varios Municipios pobres no podrá dar jamás, como resultado, un Municipio rico, siendo evidente que en el mismo volumen con que se amplíen los recursos quedarían aumentadas las necesidades y porque si se pretende amparar varias entidades deficitarias a la sombra de otra opulenta, esta última nunca aceptará, de buen grado, a los molestos advenedizos, que vendrían a acrecentar la carga tributaria de su vecindario sin beneficio alguno para el mismo» (Albi, 1966: 269-293).

En otros términos, utilizar la Mancomunidad como fórmula para reducir déficit en el mejor de los casos sólo provoca un traslado del problema puesto que la asociación nace hipotecada si sólo dispone de los recursos facilitados por los Municipios. Entonces, ¿por qué llevan funcionando casi veinte años la red de MM. Integrales auspiciada por la Junta de Extremadura? Pues porque desde el año 2003 los presupuestos autonómicos ininterrumpidamente vienen incluyendo partidas destinadas a la financiación de estas entidades asociativas. Esta dependencia permanente en materia de financiación impide valorar la viabilidad sobre datos reales, no sólo de los Municipios que la conforman sino también de la entidad mancomunada, además de provocar -no pocas veces- la congestión y la descoordinación en la gestión de la Mancomunidad (Bayona, 2012: 239).

Es cierto que la creación de una estructura mayor permitió asumir servicios que de manera individual no se podían prestar, lo que OATES denominó el «efecto zoo» (Gilbert, 2011: 41). Sin embargo se atribuyeron ventajas económicas a las Mancomunidades tales como la reducción de costes en base a la economía de escala aplicada a los servicios, o el incremento del ahorro al reducir gasto corriente, que no han sido así, pues no sólo se incrementa la nómina de personal sino también la de cargos políticos. Lo cierto es que la experiencia extremeña ha demostrado que la dinámica asociativa no ha contribuido a la reducción de las carencias económicas de los pequeños Municipios pues han aparecido nuevos gastos, no se ha mejorado la capacidad recaudatoria y, además, se ha constatado la dificultad para la rendición y la fiscalización de sus cuentas. Al generarse nuevas Entidades locales y no suprimir ninguna, el asociacionismo arrastra sin solventar los problemas del pequeño Municipio, especialmente en materia financiera pues los recursos siguen siendo limitados, los costes se incrementan; y esto acarrea mayor dependencia de otros niveles de gobierno.

En definitiva y de cara a una revisión de esta estrategia, que resulta inaplazable vistas las cifras de población, cabría reflexionar sobre qué pasará cuando los Municipios asociados tengan que soportar íntegramente el mantenimiento y los gastos adicionales de administración de la Mancomunidad y sus infraestructuras, sin contar con la ayuda financiera de otras Administraciones. Ante este hipotético escenario son dos las alternativas, bien incrementar las aportaciones de cada Municipio a la entidad común, o bien aumentar el número de miembros con el consecuente añadido de costes por la ampliación del territorio y la vecindad a cubrir (Lozano, 2005: 13). ¿Asumirían los miembros estos acuerdos? Creemos que no.

Las carencias descritas para la planta de MM. Integrales ponen de manifiesto la necesidad de repasar la estrategia territorial aplicada en Extremadura, por tanto no debemos olvidar que el objetivo principal fue y es dar solución a los problemas que acarrea el inframunicipalismo. Llegados a este punto y tras un periodo suficientemente largo, planteamos la necesidad de redefinir esta estrategia autonómica aprovechando las sinergias creadas por el asociacionismo y así dar un paso hacia la reducción de la actual planta local en Extremadura. No estamos planteando llevar a la práctica una mera teoría jurídica, sino implementar una estrategia desarrollada con éxito en el resto de países europeos ( $v$. gr:: Suecia, a mediados del s. Xx, la cooperación intermunicipal fue el precedente y el impulso de los procesos de fusión realizados (Moisio, 2011: 26). Sin embargo en España todavía no se ha conseguido dar el paso desde ninguna Administración. Tan solo encontramos el Informe ROCA, solicitado en el año 2000 por el Gobierno de Cataluña, donde se proponía la reordenación por fusión de la planta local tomando como base el esquema comarcal previo; esto es, generar un estrategia común para cada grupo de Municipios aprovechando la práctica existente en cooperación intermunicipal y dando uso a la cobertura que en materia de gestión e infraestructura ya existía (Roca, 2000: 20). Quedó todo en saco roto. Sin embargo desde aquí insistimos en la posibilidad y, asumiendo las palabras de Parada Vázquez y Checa González (Checa, 2012: 95), consideramos que la intermunicipalidad es un fraude salvo que sea obligatoria y se entienda como una primera fase para la fusión de Municipios.

Si llegamos a la conclusión de que el asociacionismo municipal no ha funcionado como estrategia para reordenar la planta municipal extremeña y tampoco sirve para superar los problemas del inframunicipalismo, toca revisar y poner en valor tantos esfuerzos y tantos recursos empleados durante años en promover esta 
REALA. Nueva Época - N. 14, octubre 2020 - ISSN: 1989-8975 - DOI: https://doi.org/10.24965/reala.i14.10825 - [Págs. 161-179]

Mancomunidades integrales en Extremadura: estrategia, trayectoria y revisión

Francisco Javier Durán García

vía mancomunada. A nuestro juicio, la solución pasa por redirigir la voluntad de los Municipios asociados en las actuales MM. Integrales hacia un proceso de fusión municipal para alcanzar una administración municipal única donde se integren varios núcleos de población (llamémosle «pueblos», por ejemplo, evitando la denominación peyorativa de «Entidad Local Menor»). Un proceso que consideramos técnicamente sencillo si se aprovecha la configuración común y los recursos humanos que ya comparten; especialmente cuando la planificación de la red de Mancomunidades se ha realizado siguiendo criterios de homogeneidad, cercanía y planificación territorial.

En conclusión, si entendemos la cooperación municipal como un punto y seguido en materia de ordenación territorial, la Junta de Extremadura, previo proceso de depuración del sobredimensionado número de entidades, dispone de capacidad económica y herramientas legales suficientes para acometer un proceso de fusiones municipales y así acabar con las consecuencias negativas del inframunicipalismo.

\section{REFERENCIAS BIBLIOGRÁFICAS}

ALBI, F. (1966): La crisis del Municipalismo. Madrid: IEAL.

ALMEIDA CERREDA, M. (2013): "La reforma de la planta, estructura competencial, organización y articulación de la Administración local", en DÍEZ SÁNCHEZ, J. J. (coord.): La planta del Gobierno local, págs. 61-122. Madrid: Fundación Democracia y Gobierno Local.

ARENILLA SÁEZ, M. (2012): "El pequeño Municipio: núcleo democrático vs. prestación de servicios", en FUNDACIÓN DEMOCRACIA Y GOBIERNO LOCAL: Documento técnico. Elementos para un debate sobre la Reforma Institucional de la Planta Local en el Estado Autonómico. págs. 159-220. Madrid: Fundación Democracia y Gobierno Local.

BAYONA ROCA, A. (2012): "La planta municipal: análisis y propuestas para hacer más eficiente el gobierno municipal en el Estado autonómico", en FUNDACIÓN DEMOCRACIA Y GOBIERNO LOCAL: Documento técnico. Elementos para un debate sobre la Reforma Institucional de la Planta Local en el Estado Autonómico, págs. 221-247. Madrid: Fundación Democracia y Gobierno Local.

BOIX PALOP, A. (2014): "Objetivos y realidad de la reforma local. Insuficiencias y concreción práctica de la Ley 27/2013 de racionalización y sostenibilidad de la Administración local”, en FUNDACIÓN DEMOCRACIA Y GOBIERNO LOCAL: Anuario del Gobierno Local 2013, págs. 89-127.

CAYETANO ROSADO, M. (2007): "Emigración extremeña durante el desarrollismo español (1961-1975)", en Revista de Estudios Extremeños, vol. 63, núm. 3, págs. 1.275-1.310. URL: https://dialnet.unirioja.es/servlet/ articulo?codigo $=3300097$.

CHECA GONZÁLEZ, C. (2019): "La inconsistente y banal ley de garantía de la autonomía municipal de Extremadura", en Anuario de la Facultad de Derecho de la Universidad de Extremadura, núm. 35, págs. 573-604. URL: https:// publicaciones.unex.es/index.php/AFD/article/view/101. DOI: https://doi.org/10.17398/2695-7728.35.573.

CHECA GONZÁLEZ, C. (2012): "La reforma de la Hacienda local para mejorar su suficiencia financiera", en OL, Revista Tributaria Oficinas Liquidadoras, núm. 37, págs. 82-105.

CHINCHILLA PEINADO, J. A. (2014): "Las mancomunidades de municipios tras la Ley de racionalización y sostenibilidad de la Administración Local", en CARRILLO DONAIRE, J. A. y NAVARRO RODRÍGUEZ, P. (coord.): La reforma del Régimen Jurídico de la Administración Local: El nuevo marco regulatorio a la luz de la Ley de racionalización y sostenibilidad de la Administración Local, págs. 265-300. Madrid: Wolters Kluwer. 1. a ed.

DURÁN GARCÍA, F. J. (2019): "Autonomía municipal y despoblación rural en España", en ORTEGA BURGOS, E. (dir.): Actualidad administrativa: 2019, págs. 131-149. Madrid: Tirant Lo Blanch. 1. ${ }^{\mathrm{a}}$ ed.

DURÁN GARCÍA, F. J. (2016): La fusión de Municipios como estrategia. Madrid: Dykinson (Monografías). 1. a ed.

GILBERT, G. (2011): "Más allá de las asociaciones intermunicipales hacia los Municipios de dos niveles de gobierno: el caso francés", en INSTITUTO DE ECONOMÍA DE BARCELONA: Informe IEB sobre Federalismo Fiscal 2011, págs. 32-43. Barcelona: IEB. URL: https://ieb.ub.edu/wp-content/uploads/2012/02/InformeFF2011_esp.pdf.

HEINELT, H. (2012): "Posibles reformas de la estructura institucional del Gobierno local en España en el seno del «Estado de las Autonomías». Perspectiva comparada a la luz de los debates y recientes reformas sobre el Gobierno local en los Estados miembros de la Unión Europea", en FUNDACIÓN DEMOCRACIA Y GOBIERNO LOCAL: Documento técnico. Elementos para un debate sobre la Reforma Institucional de la Planta Local en el Estado Autonómico, págs. 68-107. Madrid: Fundación Democracia y Gobierno Local.

JIMÉNEZ ASENSIO, R. (2012): "Estudio introductorio: reforma de la planta local y competencias municipales. Primeras reflexiones de urgencia sobre una propuesta", en FUNDACIÓN DEMOCRACIA Y GOBIERNO LOCAL: Documento técnico. Elementos para un debate sobre la Reforma Institucional de la Planta Local en el Estado Autonómico, págs. 13-65. Madrid: Fundación Democracia y Gobierno Local.

LÓPEZ ARRIBAS, C. (2009): "La reorganización territorial: Hacia unos ayuntamientos eficientes y viables. La fusión selectiva de Municipios", en RODRÍGUEZ GONZÁLEZ, R. (dir.): Reformar la Administración territorial. Municipios eficientes y viables, págs. 185-203. Oleiros: Netbiblo. $1{ }^{\text {a }}$ ed. 
LOZANO CRESPO, M. (2005): "Competencias y financiación local. La historia interminable de una quimera", en El Consultor de los Ayuntamientos y de los Juzgados, núm. 8, págs. 1.301-1.315. Fecha de consulta: 14-05-2020.

MOISIO, A. (2011): "Asociaciones municipales: la experiencia de los países nórdicos", en INSTITUTO DE ECONOMÍA DE BARCELONA: Informe IEB sobre Federalismo Fiscal 2011, págs. 22-31. Barcelona: IEB. URL: https://ieb. ub.edu/wp-content/uploads/2012/02/InformeFF2011_esp.pdf.

ORDUÑA PRADA, E. (2009): "EI Municipio como marco relacional”, en RODRÍGUEZ GONZÁLEZ, R. (dir.): Reformar la Administración territorial. Municipios eficientes y viables, págs. 99-128. Oleiros: Netbiblo. 1. ${ }^{a}$ ed.

PARADA VÁZQUEZ, J. R. (2007): La segunda descentralización: del Estado autonómico al municipal. Pamplona: Thomson Reuters (Cuadernos Civitas). 1. ${ }^{\text {a }}$ ed.

ROCA I JUNYENT, M. (2000): Informe sobre la revisió del model d'organizació territorial de Catalunya. Barcelona: Govern de la Generalitat de Catalunya. Fecha de consulta: 25-04-2020. URL: https://www.raco.cat/index.php/ TreballsSCGeografia/article/view/10429.

RODRÍGUEZ GONZÁLEZ, R. (2006): "El territorio local en Europa. Reestructuración de su base organizativa y posibilidades para España”, en Xeográfica, Revista de Xeografía, Territorio e Medio Ambiente, núm. 6, págs. 115132. Fecha de consulta: 14-05-2020.

ZAMORA ROSELLÓ, M. R. (2013): "La reestructuración de la planta del gobierno local y las mancomunidades de Municipios", en DÍEZ SÁNCHEZ, J. J. (coord.): La planta del Gobierno local, págs. 139-150. Madrid: Fundación Democracia y Gobierno Local. 